\title{
DE “CASA MANIFESTO” A “ESPAÇO DE DESAFETOS”: OS IMPACTOS CULTURAIS, POLÍTICOS E URBANOS VERIFICADOS NA TRAJETÓRIA DO SOLAR MONJOPE (RIO, ANOS 20 - ANOS 70)
}

From "Manifesto House" to "Disaffection Space": the cultural, political and urban impacts verified in the trajectory of Solar Monjope (Rio, 1920's-1970's) 


\title{
RESUMO
}

Este artigo apresenta o "circuito social" de uma obra de arquitetura neocolonial, o Solar Monjope, edificada nos anos 1920 no Jardim Botânico pelo médico e diletante das artes José Marianno Filho. 0 solar esteve envolto em controvérsias desde sua construção, e em especial quando de sua demolição nos anos 1970, e a partir dele estudamos os meandros institucionais dos órgãos de preservação atuantes no território carioca, 0 IPHAN e o predecessor do INEPAC, nos anos 1970, analisando as razões para a demanda pró-preservação de não especialistas como forma de entender a percepção da sociedade sobre o patrimônio.

PalaVRAS-CHAVE: Solar Monjope; INEPAC; IPHAN; neocolonial; José Marianno Filho.

\begin{abstract}
This article presents the "social circuit" of a piece of neo-colonial architecture, the Solar Monjope, built in the 1920s at the Botanical Garden in Rio de Janeiro, by the doctor and supporter of arts José Marianno Filho. As the house has been object of controversy since it was built, and specially when it was demolished in the 1970s, we take it to study the institutional intricacies of active conservation agencies in Rio de Janeiro, the IPHAN and the predecessor of INEPAC, in the 1970s, and analyze the reasons of the demand for preservation by non-experts, in order to understand the perception of heritage by society.
\end{abstract}

KeYwOrDs: Solar Monjope; INEPAC; IPHAN; neocolonial; José Marianno Filho.

\section{RÉSUMÉ}

Cet article présente le "circuit social" d'une œuvre d'architecture néocoloniale, la Maison Monjope, construite aux années 1920 dans le quartier du Jardin Botanique, à Rio de Janeiro, par le médecin et amateur des arts José Marianno Filho. En partant du fait que la maison a été objet de controverse depuis sa construction, et en particulier quand elle a été démolie aux années 1970, nous étudions les subtilités institutionnelles des organismes de conservation actifs à Rio de Janeiro, I'IPHAN et le prédécesseur de I'INEPAC, aux années 1970, et analysons les raisons des demandes de préservation des non-experts, a fin de comprendre la perception du patrimoine par la société.

Mots-CLÉs: Solar Monjope; INEPAC; IPHAN; néocolonial; José Marianno Filho. 
ntender as razões que levaram edifícios ao desaparecimento pode parecer, num primeiro momento, uma atividade prosaica, quase uma curiosidade de fundo afetivo. Entretanto, nos últimos tempos, a emergência de livros, blogs, sites, reportagens especiais de jornais e revistas têm mostrado que as edificações exercem papel importante na criação de identidades e na formulação de memórias urbanas. Assim, estudar edifícios pode se tornar uma grande estratégia para a compreensão do corpus social e, por isso, se torna um problema do campo histórico. Esta afirmação está embasada em uma questão metodológica, uma vez que compreender o fenecimento, a evanescência, o desaparecimento leva, necessariamente, à reflexão do peso que as estruturas urbanas construídas possuem na identidade urbana e na vida cultural de milhares de pessoas. Ou seja, historiando os processos de destruição de edifícios consegue-se entender, paradoxalmente, como socialmente as edificações exercem papel no "espaço público", tornando-se parte da vida cotidiana de pessoas que, mesmo que os conheçam apenas de fora, sem nunca terem adentrado seus umbrais, se tornam interligadas à sua dimensão simbólica e cotidiana. Adiciona-se a isso, ainda, uma percepção das razões históricas para que edifícios, mesmo que desaparecidos, persistam no imaginário urbano por décadas. Em outras palavras, pode-se compreender, por meio de edifícios desaparecidos, como foram tecidas relações entre habitantes e cidades, a ponto de notar que, com o desaparecimento, um elo de pertencimento se rompeu e criou fraturas memoriais, muitas vezes irrecuperáveis, mas que acionam atitudes tanto no campo da memória quanto nas atividades de colecionismo, divulgação, ressignificação e organização de narrativas.

Metodologicamente, a maneira mais aparelhada para o estudo dessas categorias que expusemos é por meio daquilo que se convencionou chamar de "circuito social da obra", isto é, mediante a investigação histórica da idealização, da produção, da construção, da circulação e da recepção dessas arquiteturas, que são vistas como deflagradoras de mecanismos de memória, que repercutem no meio social para além do imaginado pelo projetista. Nós as vemos como portas de acesso privilegiadas às histórias sociais das cidades.

Este artigo, assim, apresenta o "circuito social" de uma obra de arquitetura singular, conhecida por décadas como Solar Monjope. Edificada nos anos 1920 no Jardim Botânico pelo médico e diletante das artes José Marianno Carneiro da Cunha Filho, a casa foi envolta em 
controvérsias desde sua construção, e em especial quando de sua demolição nos anos 1970. Enfocando em especial os meandros institucionais dos órgãos de preservação acionados para a preservação do imóvel, o IPHAN e a Divisão do Patrimônio Histórico e Artístico da Guanabara, predecessor do INEPAC - Instituto Estadual de Patrimônio Cultural -, mostramos como os órgãos de preservação atuantes no território carioca nos anos 1970 lidaram com esse edifício que, embora vinculado a discussões acadêmicas e eruditas sobre os valores arquitetônicos, acabou sendo alvo de demandas de preservação de não especialistas, advindas, de certa forma, de grande ala da sociedade carioca.

\section{O MOVIMENTO EM PROL DA ARQUITETURA TRADICIONAL BRASILEIRA}

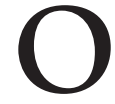

Solar Monjope não pode ser entendido sem se fazer menção ao seu idealizador. A conexão entre "obra" e "proprietário", que no campo arquitetônico é basilar, no caso que passamos a analisar se torna ainda mais visceral. Sua construção foi um fatto urbano almejado, pensado e divulgado como uma grande demonstração de poderio e uma possível "vitória" do movimento neocolonial de Arquitetura, que teve em José Marianno Filho um propugnador, defensor, polemista e financiador. Curiosamente, o fato de o Solar Monjope ter desaparecido também guarda, simbolicamente, conforme opinião comum, relações indeléveis com o controverso "legado" de seu idealizador. Essas relações de causa e efeito foram analisadas neste artigo e descortinaram uma densidade bem maior do que a contida na historiografia da preservação. Dessa maneira, convém principiar apresentando quem foi esse ator social tão controverso que apenas nos últimos anos tem sido estudado mais profundamente (Mingorance, 2012; Atique, 2011 e 2010, Kessel, 2009).

José Marianno Carneiro da Cunha Filho nasceu em 13 de abril de 1881 em Pernambuco, em uma propriedade denominada Engenho Monjope, que desde o século XVIII pertencia à sua família. Era o primogênito do abolicionista pernambucano José Marianno com Olegária da Costa Gama. Em 1893, sabe-se que a família estava radicada no Rio de Janeiro (Bandeira, 2008: 35).

José Marianno Filho formou-se médico pela Faculdade Nacional de Medicina, no Rio, provavelmente na metade da década de 1900 (Mingorance, 2012; Atique, 2011 e 2010). Em 9 de julho de 1908, contraiu casamento com Violeta Siciliano, segunda filha de Alessandro Siciliano, conde "papal" e multiempresário radicado em São Paulo. 0 casamento de José Marianno Filho com Violeta tornou-o membro do rol de acionistas das empresas da família de sua esposa, garantindo-lhe capital simbólico, cultural e econômico (Mingorance, 2012). 
Na década de 1920, José Marianno Filho passou a aparecer no cenário cultural carioca com mais intensidade. Já conhecido dos artistas e literatos que frequentavam o cartório de seu pai na Rua do Rosário, foi galgando degraus importantes no cenário artístico. Em 1920 apareceu como um dos membros fundadores do Rotary Club do Rio de Janeiro e, em 1921, como sócio fundador da Sociedade Central de Arquitetos e do Instituto Brasileiro de Arquitetos, na mesma cidade (Atique, 2007). Em 1921 se tornou sócio da Sociedade Brasileira de Belas Artes, fundada em 1919 e também sediada no Rio de Janeiro, da qual viria a ser presidente alguns anos depois.

Nessa mesma década, também principiou sua atividade de articulista e de crítico de arte e arquitetura, escrevendo para os jornais O Dia, O Jornale A Noite, e alavancando sua desejada carreira de "agitador cultural". Como mostrou Carlos Kessel, nos anos de 1921 e 1922, em especial com as festividades do Centenário da Independência do Brasil, José Marianno encontrou um lugar junto à classe arquitetônica. Sua louvação e, ao mesmo tempo, sua crítica ácida aos pavilhões de exposição montados no sopé do antigo Morro do Castelo levaram-no a assumir o posto de propugnador do movimento em defesa da Arquitetura Tradicional Brasileira (Kessel, 2009).

Para José Marianno Filho e seus seguidores, a Arquitetura Tradicional Brasileira vinha recuperar uma dimensão que se havia perdido quando, no século XIX, uma formação erudita de caráter francês foi introduzida no Brasil por conta da Academia Imperial de Belas Artes ( 0 Jornal, 8 de julho de 1931, s. p.). Comumente, nossa historiografia designa as arquiteturas criadas segundo essa proposta de José Marianno como "neocolonial"; outras vezes ainda, elas aparecem sob a denominação "estilo neocolonial". José Marianno Filho, entretanto, defendia a tese de que a expressão neocolonial, formada com o emprego do prefixo "neo", alinhava a típica manifestação nacionalista que defendia no rol das arquiteturas de estilo praticadas no ecletismo arquitetônico e invocado pela seara dos "neos": neoclássico, neorromânico, neogótico, entre outros (Cunha Filho, 1942). Para ele, o ecletismo, ao introduzir formas que remetiam a outros países, se não destruiu, esmaeceu a plena demonstração da expressão de uma "raça brasileira" (Idem). A solução seria, então, não apenas combater a continuidade desse ecletismo, que a República incentivou grandemente em suas obras, mas introduzir um novo léxico, erradicando o uso das expressões "neo" e "estilo". Acreditava José Marianno estar permitindo o reaparecimento das "expressões do povo", recuperando nos "tempos modernos" uma forma e uma sensibilidade estética de um idílico Brasil Colônia (Cunha Filho, 1942; Costa, 1927: 295).

José Marianno Filho, ao contrário do engenheiro Ricardo Severo, considerado o introdutor da arquitetura neocolonial no Brasil (Melo, 2007), defendia que era a cidade colonial, com sua convivência entre obras opulentas e casas vetustas, que deveria ser tomada como 
lastro da cidade moderna em construção. Na Colônia, para José Marianno, residia a "essência" do Brasil que o ecletismo havia borrado. Severo, português, fazia apologia dos edifícios e da herança lusa no país, segundo ele, fonte inconteste de nossa arte e arquitetura e, portanto, modelo para a continuidade estética nos tempos modernos (Pinheiro, 2011; Atique, 2011).

Essa base argumentativa separava, então, os dois expoentes do movimento arquitetônico que estamos analisando. Na década de 1920, José Marianno considerava-se o "vencedor" dessa campanha tradicionalista, e julgava ser o Rio de Janeiro o locus principal para a implantação de um edifício modelar para sua batalha em prol da arte e da arquitetura nacional (Atique, 2011; Costa, 1927). Nascia, dessa maneira, a ideia de construção do "Solar Brasileiro", cerne do Solar Monjope, efetivamente construído (Kessel, 2002 e 2009; Atique, 2010).

\section{A "CASA-MANifesto" DO NeOcolonial}

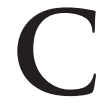

omo nos mostra Carlos Kessel (2009: 174), até 1923 José Marianno tinha promovido quatro concursos junto à Sociedade Brasileira de Belas Artes. O concurso de 1923 destinava-se à empreitada mais importante de sua "campanha tradicionalista". O objetivo era a escolha de um projeto para um "Solar Brasileiro". O certame, intitulado Prêmio Heitor de Mello, deveria prover, para o centro de um parque, uma edificação solarenga, de dois pavimentos, com obrigatoriedade de uso de motivos da arquitetura tradicional (colonial) sacra ou civil verificados no Brasil (Kessel, 2009: 131; A Noite, 15 out. 1923). 0 vencedor da competição foi o jovem arquiteto Ângelo Bruhns.'

A residência foi construída às margens da Lagoa Rodrigo de Freitas, no Rio de Janeiro, com entrada principal pela Avenida Jardim Botânico 225, na mesma área ocupada durante os períodos colonial e imperial pela Chácara da Bica (Decourt, 2012). Transformado por José Marianno em "manifesto construído" de sua campanha, o Solar Monjope foi palco importante para diversas facetas do cenário arquitetônico, cultural, político e ambiental da cidade do Rio de Janeiro. Curiosamente, foi também atrelado àquilo que se entendia como política preservacionista nos anos iniciais do século XX, sobretudo anteriores ao Decreto-Lei $n^{\circ} 25$, de 1937, que organizou o Serviço do Patrimônio em nível federal no Brasil. Esta última afirmação necessita ser explorada com um pouco mais de calma.

Maria Lucia Bressan Pinheiro (2011) mostrou que nos anos 1910 e 1920 o colecionismo praticado por diletantes da arte e por intelectuais estava revestido de uma dimensão preservacionista, e não apenas no Brasil. Nesse sentido, esclarece Manuela Hargreaves (2014: 2), "a coleção reflete um modelo do mundo feito à medida de quem a realiza", e o ato de colecionar "poderá até ser uma forma de corrigir [o mundo], de estabelecer uma nova ordem, 
de perpetuar uma vida, ou de dar um sentido ao tempo". Esse colecionismo, que advinha da tradição renascentista, assumiu novo caráter no século XIX com a emergência e o papel econômico do connoisseur, e foi praticado nas primeiras décadas do século XX, no Brasil, como forma de amealhar "riquezas" artísticas que eram vistas como fadadas ao desparecimento. As coleções de arte e de elementos arquitetônicos apareceram nos anos 1920 como uma "marca da individualidade" do colecionador e, via de regra, de sua almejada projeção social no papel de "resgatar" objetos "perdidos". Tal prática encontrou em José Marianno Filho demonstração inequívoca, e de certa maneira possibilitou a criação de um "ambiente total" demonstrativo da arte nacional que queria ver perpetuada, e, ao mesmo tempo, de sua ilustração e poderio econômico no cenário cultural brasileiro e das Américas. Como exemplo, convém analisar a avaliação de Angyone Costa, que no livro $A$ inquietação das abelhas, de 1927, compilou depoimentos de artistas do círculo de José Marianno Filho:

O Sr. José Marianno Filho, com uma dedicação, um carinho de convertido, dedicado à crença nova, sem discutir sacrifícios, nem olhar as despesas, vem pacientemente recolhendo material artístico, representado em pedras, mosaicos, móveis antigos com os quais ultima, neste momento, a sua grande criação, o solar de Monjope (...) 0 solar de Monjope está intimamente ligado a José Marianno e, já agora, não é possível a ninguém ocupar-se da personalidade encantadora desse "condottiere" da beleza, ritualista da harmonia, que ele ama e sabe definir na sua forma construtiva mais elevada, a casa, sem falar do solar modelo que o seu bom gosto edificou na Gávea. A casa de José Marianno Filho vai ser uma grande força estética a modificar, fatalmente, a arte de construir, no Brasil. Já está sendo, mesmo, a principal fonte fornecedora de emoções, a escola e o cadinho onde se vão temperar as inteligências que querem, com sinceridade, dar uma arquitetura ao país (Costa, 1927: 291-292, grifos nossos).

A reunião de peças originais, compradas em antiquários, mas sobretudo em edifícios sacros e em casas em demolição Brasil afora, foram amealhadas por José Marianno e diligentemente dispostas no Solar. ${ }^{2}$ Analisando a citação de Angyone Costa, torna-se interessante perceber que o escritor informa que a casa "já está sendo mesmo, a principal fonte fornecedora de emoções, a escola e o cadinho" da arquitetura brasileira (Costa, 1927: 292). Esta citação nos revela, então, um curioso movimento de visitação, divulgação e, consequentemente, circulação da arquitetura que constitui aquilo que estamos investigando, ou seja, o circuito social da obra.

O filme Sangue Mineiro, de 1929, dirigido por Humberto Mauro, foi rodado no Solar Monjope ainda em seus primeiros anos. Também numa reportagem da revista 0 Cruzeiro, em 1930, pode-se vislumbrar a residência, tanto interna quanto externamente (O Cruzeiro, 1930, s/p). Sendo assim, convém mostrar que a "Casa Manifesto" figurou, por intenção deliberada de José Marianno Filho, em eventos do III Congresso Pan-Americano de Arquitetos, em 1927, 
durante o qual o Solar Monjope, mesmo em obras, foi visitado por uma comitiva de arquitetos estadunidenses $^{3}$ (O Jornal, 28 jun. 1927: 3).

Ainda em 1927, no mês de julho, Donat-Alfred Agache (1875-1959) foi levado pelo Instituto Brasileiro de Arquitetos a visitar as obras do Solar. 0 inglês Rudyard Kipling (18651936), autor de Brazilian Sketches, que esteve no Brasil em 1927, também visitou a casa e, segundo a revista Ilustração Brasileira (s.n, 1927, s/p), a edificação nele "provocou (...) elogios inteiramente aberrantes da sobriedade educada do calmo temperamento inglês".

Em 1928, José Marianno, que transitava com desenvoltura junto ao Ministério da Educação, conseguiu inserir seu Solar no roteiro das "Excursões Instrutivas" que a Associação Brasileira de Educação, por meio da Seção de Ensino Primário, promovia. Uma nota publicada no Correio da Manhã no dia 22 de junho daquele ano informava que as professoras associadas visitariam o Solar Monjope, recebendo do próprio Marianno uma palestra sobre a "arquitetura do século XVIII". A ideia, segundo a nota, era permitir que as mestras recebessem instrução in situ, para que em "excursões posteriores" pudessem "replicar o conhecimento" adquirido aos estudantes primários. Estima-se que, com essa divulgação e a consequente visitação à casa de Marianno, milhares de estudantes tenham conhecido o Solar, recebendo ensinamentos direcionados à divulgação do discurso nacionalista que José Marianno advogava.

Essas reportagens enfocando José Marianno Filho e sua "casa-manifesto" nos jornais de circulação nacional produziam curiosidade e transformavam a casa em ponto de interesse também para pesquisadores, além do público urbano. Em 17 de junho de 1929, a casa recebeu a visita de mais personalidades ligadas a instituições museológicas, como a vice-diretora do Roerich Museum, de Nova York, Sra. Francis Grant, que se encontrava "em missão de estudo no Rio de Janeiro" (Correio da Manhã, 18 jun. 1929: 7).

Personalidades diversas passaram pelo local, mas eram as caravanas que acabavam gerando impacto profundo nas publicações e, certamente, nos visitantes, que eram recebidos pelo anfitrião José Marianno. Entre os eventos de grande proporção, esteve certamente o IV Congresso Pan-Americano de Arquitetos. Como apontado por diversos autores, o congresso foi uma espécie de coroação de José Marianno Filho - pelo menos entre os sul-americanos - como grande nome ligado à regulamentação da profissão de arquiteto, à defesa das artes locais e à preservação patrimonial. José Marianno capitalizou-se simbolicamente com o evento, em especial pela "folclórica" festa de São João que organizou no Solar Monjope ( $O$ Paiz, 21 jun. 1930: 5).

A partir dos anos 1930, a casa começou a perder importância perante os arquitetos brasileiros, muito embora fosse consagrada pelos latino-americanos e estadunideneses, que continuaram a visitá-la quando de suas passagens pelo Rio. Curiosamente, foi a partir da 
década de 1930 que publicações não especializadas passaram a abordar a casa, e se prolongaram mesmo após a morte de José Marianno Filho, em 5 de junho de 1946, até a demolição, nos anos 1970.

Segundo relato de José Marianno, neto do idealizador, que pudemos entrevistar, o Solar também era procurado no final dos anos 1960 e início dos 70 para que noivas pudessem ser fotografadas na escadaria principal, da rua Jardim Botânico. 0 mesmo informante nos contou que fotonovelas foram feitas valendo-se da casa como cenário. Uma edição da revista Sétimo Céu de abril de 1970 mostra detalhes do Monjope, enquanto transcorria um romance envolvendo a cantora Adriana e o ator Jerry Adriani (Sétimo Céu, abr. 1970).

Essa trajetória, de "manifesto construído" do neocolonial, locus de sensibilização da sociedade artística nacional e estrangeira, a espaço para festas e recepções da alta sociedade, mas também a cenário de filmes, fotonovelas, álbuns de casamento, fez do lugar um espaço plural, conhecido em diversos setores da sociedade, levando claramente a compreender as manifestações pró-preservação que ocorreram no início daquela década de 1970, quando a casa foi anunciada como tendo "seus dias contados" (em dólar).

\section{DESFAZENDO O PATRIMÔNIO}

U ma nota publicada no Jornal do Brasil em 22 de outubro de 1973, na coluna de Zózimo Barroso do Amaral, ${ }^{4}$ chamou a atenção de alguns cariocas. Intitulada "'Transa' Imobiliária", informava que "a famosa chácara do Sr. José Mariano Filho - enorme área verde em plena rua Jardim Botânico (entre as ruas Maria Angélica e General Tasso Fragoso) - está sendo negociada com uma das maiores companhias construtoras em ação no Rio. Valor da transação: Cr\$27 milhões". ${ }^{5}$

Poucos dias depois, um ofício datado de 5 de novembro de 1973, redigido pelo Instituto de Arquitetos do Brasil (IAB), Seção Guanabara, assinado pelo presidente da entidade, João Ricardo Serran, solicitava ao governador Antônio de Pádua Chagas Freitas (1914-1991) o tombamento do Solar Monjope pelo Estado da Guanabara (Processo Iphan 895-T-74). Nove dias depois, Zózimo retomou a questão em sua coluna, confirmando o valor a ser pago pela Construtora Zein aos herdeiros de José Marianno, que já não residiam no Solar ${ }^{6}$ (Jornal do Brasil, 14 nov. 1973, s. p.).

Esses documentos geraram uma verdadeira especulação midiática acerca da casa. Cheio de conflitos e démarches, o Solar Monjope serve com eloquência à demonstração de que na década de 1970 não apenas edifícios do setor público causaram polêmica no que se refere à aplicabilidade do tombamento em solo carioca. ${ }^{7}$ 
No dia 17 de novembro de 1973, nota publicada no Jornal do Brasil informava que o Estado da Guanabara havia acatado a solicitação do IAB de tombamento do Solar Monjope, abrindo processo para estudar a questão, registrado no Boletim Oficial do Estado da Guanabara. Segundo a breve nota do jornal, em 16 de novembro fora emitido o aviso de tombamento provisório, mas José Marianno Neto alegava que ainda não o havia recebido. $A$ reportagem cedeu espaço, então, ao herdeiro de Cunha Filho para comentar a iniciativa. Disse Marianno Neto que "estava surpreso com a notícia do possível tombamento do Solar, já que a sua propriedade tem apenas 50 anos de existência, 'o que não justifica providência dessa natureza'" (grifos nossos).

Marianno Neto evocava um princípio que, embora nunca tivesse feito parte da legislação referente à preservação dos bens culturais no Brasil, era recorrente como discurso na sociedade, quase com um antídoto ao tombamento. Aliás, a única menção a uma temporalidade adequada para a patrimonialização de um bem, mais especificamente ao marco de 50 anos, advinha do anteprojeto para a organização do Patrimônio elaborado por Mario de Andrade ${ }^{8}$ em 1936, o qual, após ser revisto por Rodrigo Mello Franco de Andrade (1898-1969), teve tal condição descartada (Cavalcanti, 1993: 39-56).

No dia 21 de novembro, contudo, uma reviravolta colocou o Solar Monjope novamente nas páginas dos jornais. Divulgava o jornal O Dia que o secretário da Cultura da Guanabara, Fernando Barata, havia mandado sustar o processo em tramitação. A alegação do secretário da pasta de Cultura, Desportos e Turismo era que o Decreto-Lei n 2, de 11 de abril de 1969, ${ }^{9}$ carecia de regulamentação, incorrendo em "injuridicidade, não atingindo os seus altos objetivos" (O Dia, 21 nov. 1975). A medida ainda abriu um precedente maior, pois não apenas a notificação do tombamento do Solar Monjope tornava-se sem efeito, o que permitia a venda da propriedade e sua demolição para a ereção de seis torres de apartamentos, como extirpou a proteção por todo o Estado da Guanabara, causando verdadeira corrida de incorporadoras, construtoras e demais subsidiárias envolvidas com o mercado imobiliário.

Em 17 de fevereiro de 1974 ocorreu a derrubada do muro, na esquina das ruas Tasso Fragoso com Jardim Botânico. Começava então, efetivamente, a demolição do Solar. 0 professor Olínio Gomes Paschoal Coelho, antigo funcionário da Divisão de Patrimônio Histórico e Artístico do Estado da Guanabara, relembrou outros impactos sociais que a demolição despertou:

Aí, na sexta-feira, entra um trator, derruba-se o muro e começa-se a jogar abaixo aquilo tudo. Tenho fotografias dessa demolição; estão no livro. Aí, nós fomos para lá fazer "escândalo", um grupo de professores da FAU [UFRJ] e alguns alunos nossos. O Trajano Garcia Quinhões, professor de História, ficou contra essa confusão toda. Comentava-se que o [Marcos] Tamoyo ${ }^{10}$ teria 
interesse na construção, dizem até que ele financiava o empreendimento, não sei bem. Ficou um ressentimento que mais tarde iria colaborar para a demissão do Marcello [de Ipanema] e a minha própria, pois eu era o chefe do Serviço de Tombamento e Proteção (entrevista de Olínio Coelho, apud Kushnir e Horta, 2011: 64).

Na demolição houve perdas irreparáveis, mas houve, também, ganhos sociais, se vistos numa perspectiva ampliada da seara preservacionista em solo carioca.

\section{Alguns impactos [POSITIVOS] DA DEMOLIÇÃO}

obre a polêmica que envolveu o mercado imobiliário carioca e os órgãos de proteção do
patrimônio na década de 1970, torna-se muito esclarecedor transcrever o depoimento de
Olínio Coelho. Em entrevista concedida"11 a Sandra Horta e Maria Célia Fernandes, o arquiteto
iluminou muitos dos meandros políticos ligados à questão que estamos investigando. Revelou
Coelho que:

A Divisão de Patrimônio Histórico e Artístico do Estado da Guanabara foi uma criação do governador Carlos Lacerda, exatamente para fazer uma coisa: tombar o Parque Lage. A Divisão foi criada em 31 de dezembro de 1964, pelo Anexo ao Decreto n³46. Ninguém sabia como fazer, então ele criou a Divisão como anexo de um decreto maior. Para quê? Para tombarmos o Parque Lage, o que foi feito em 15 de julho de 1965. (...) 0 governo estadual não gostou da (atuação) da Divisão de Patrimônio Histórico e Artístico, contrária à demolição do Solar de Monjope, em frente ao Parque Lage, para a construção de um conjunto de apartamentos. A Divisão fez a notificação de tombamento aos proprietários, que foi enviada ao Gabinete do governador para expedição em 14 de novembro de 1973. Depois de um encontro entre o ministro dos Transportes, ${ }^{12}$ o presidente Geisel e o governador Chagas Freitas, na ponte Rio-Niterói, em construção, veio ordem para que não fosse mais tombado o solar; que fosse cancelada a notificação expedida pelo governador. Já era diretor o Trajano [Garcia Quinhões], não era mais o Marcello [de Ipanema]. Quando então veio a ordem, ninguém do Gabinete do secretário sabia o que fazer; 0 ato estava pronto, publicado no Diário Oficial. A notificação estava feita. Aí veio um fazedor de constituições da República da ditadura, um advogado que fazia os atos institucionais, nos procurar pessoalmente para desfazer 0 ato. Não se podia desfazer a notificação. Então, inventaram que o Decreto-lei n 2 ainda não estava regulamentado. Porque, se não havia regulamentação, não se podia fazer tombamento; ${ }^{13}$ desmancha tudo. 0 Fernando Barata, secretário de Educação, não sabia o que fazer; sabia mais grego que administração de educação. 0 que fizeram? Anularam a notificação de tombamento com um despacho do secretário de Educação, em 20 de novembro de 1973, publicado no Diário Oficial (Entrevista de Olínio Coelho, apud Kushnir e Horta, 2011: 63-64). 
A imprensa não tardou a noticiar, embora sem aludir aos atores sociais, o ocorrido. Manchete do jornal Última Hora anunciava, na edição de 22 de novembro de 1973: "Chagas Freitas recua, especuladores vencem". Outros jornais cobriram o recuo do secretário Fernando Barata, arrolando o governador Chagas Freitas e denunciando a posição como demonstrativa de suposta corrupção das empreiteiras com relação ao político (Diário de Notícias, 23 nov, 1973; Jornal do Brasil, 24 nov, 1973; O Estado de S. Paulo, 29 nov, 1973).

Em 28 de novembro, João Ricardo Serran encaminhou a diversos órgãos de imprensa um texto em que discutia a relação do mercado imobiliário com o setor preservacionista. 0 texto de Serran dizia que o "investimento imobiliário" naquele momento substituía "a febre da Bolsa de Valores", e que "o tombamento de imóveis com a intenção de preservar testemunhos de nossa cultura através dos tempos passou a ser encarado como tombamento-demolição, para estimular o 'progresso da cidade'" (Serran, apud Processo Iphan 895-T-74). Prosseguia o arquiteto dizendo que aquela "singular inversão de valores" ia configurando, "pouco a pouco, nossa 'nova cultura nacional'. Cristalizada nos lamentáveis empreendimentos imobiliários, resultantes da ação do Sistema Financeiro da Habitação, em que a eficiência econômica prevalece sobre qualquer preocupação com o homem e a natureza" (Serran, apud Processo Iphan 895-T-74).

Na contraofensiva do IAB-GB, a revista Veja publicou artigo que se apresenta, ainda hoje, como um inegável libelo contra a seara preservacionista. 0 artigo, intitulado com o neologismo "Tombunismo", apareceu na edição 273, de 28 de novembro de 1973. A argumentação era curiosa, calcada na defesa dos interesses particulares, como se pode ler:

Segundo a ciência política, a fórmula convencional que permite aos governos se apropriarem dos bens dos cidadãos é o estabelecimento do regime comunista, dito vermelho. No Brasil, os governos estão adquirindo o hábito de lançar mão do alheio através de desapropriações e, agora, numa fina invenção, através do tombamento. A primeira vítima foi o Solar Monjope, uma construção de 1928, no Jardim Botânico, no Rio. Num terreno de 10.000 metros quadrados, o solar pretendia ser para seu idealizador, o milionário José Mariano Filho, um exemplo da casa brasileira. Infelizmente, resultou um bolo atrapalhado de maneirismos, varandinhas, treliças e torres imitando um claustro de igreja. (...) Evidentemente, a cidade nada terá a ganhar com a transformação dos belos jardins da casa numa taba de concreto, mas, através de raciocínios duvidosos, o governo da Guanabara resolveu fazer com que o atual proprietário, José Mariano Netto, pague de seu bolso pela destruição sistemática das obras de arte e do verde da cidade. Apesar de o secretário da Educação, Fernando Barata, ter desaconselhado o tombamento na terça-feira passada, continua em vigor um ato do governador Antônio de Pádua Chagas Freitas determinando o confisco da propriedade que, nesses casos, custa ao erário apenas a tinta da caneta (Veja, 28 nov. 1973. Disponível em: veja. abril.com.br/acervodigital/home.aspx. Acesso 20 jan 2015). 
Pelo texto fica nítida a intenção: mobilizar parte da opinião dos leitores do semanário contra a política de preservação que se praticava em solo carioca. De fato, o tombamento não é a melhor nem a mais eficiente das atitudes pró-preservação, mas ele não é, como alegava a Veja, uma atitude de retirada do direito de propriedade, pois apenas restringe, como tantos outros instrumentos da legislação incidentes sobre o urbano, a descaracterização e a demolição, não o uso e, muito menos, a transmissão da propriedade entre vivos e descendentes (Mateus, 2008; Castro, 2009). 0 raciocínio da revista era também enfraquecer os argumentos da própria entidade preservacionista atuante no então estado da Guanabara, valendo-se de um temor plenamente difundido à época, que era o da ação comunista.

Com a suspensão do tombamento, a construtora adquirira o imóvel, mas os protestos da sociedade civil e a ação do IAB-GB acabaram por gerar interrupções no processo de demolição. Fez-se necessário, então, armar uma contra-campanha à preservação, garantindo à empreiteira o cumprimento da venda assinada. Ibrahim Sued, ${ }_{1}^{14}$ que levara até as páginas da revista Manchete, em 1967, reportagem em que destacava os ambientes do "Solar Misterioso", e era habitué da mansão dos Carneiro da Cunha, também foi mobilizado. Em pequena nota publicada no jornal 0 Globo em 7 de dezembro de 1973, expunha ele que "Não é a primeira vez que o Estado tem tombado propriedades privadas e depois perdido na justiça em todas as instâncias. Bola preta. A propriedade privada deve ser respeitada e acatada" .

Faz-se necessário entender, também, dentro desse mosaico complexo da patrimonialização em estudo, qual foi o papel do IPHAN. Como nos mostra a publicação organizada por José Pessôa (1998: 283), houve a demanda pela preservação do Solar em diversas frentes. 0 IPHAN foi acionado em duas ocasiões. A primeira, em outubro de 1973, por demanda do IAB-GB. Na ocasião, designou-se Lucio Costa, aposentado da Divisão de Estudos e Tombamento, para exarar parecer. O parecer principiava de forma incisiva: "O chamado 'Solar Monjope' é um falso testemunho, exemplo de como uma casa brasileira nunca foi" (Costa, apud Pessôa, 1998: 284). Mas embora Costa fosse claro, dentro de sua argumentação de técnico da primeira geração do IPHAN, de que havia uma "impossibilidade de considerar-se tal edifício 'monumento nacional', digno de tombamento pelo IPHAN, o caso muda de figura quando encarado do ponto de vista da cidade e do seu patrimônio ambiental" (Idem, grifos nossos).

Arquitetonicamente, o bem em estudo por Lucio Costa era, em sua interpretação, um "falso testemunho", ou seja, encarnava, com sua volumetria e pertences, um papel que, no olhar purista do técnico do IPHAN, não era nem colonial, nem moderno. Esta tese tem sido analisada por estudiosos do arquiteto, e não é de nosso interesse aqui. Queremos apenas ressaltar que Costa não defendia o Solar, mas também não o repudiava. A conclusão que seu breve parecer explicita é que "é de todo interesse que o estado preserve o conjunto, não só 
porque o prédio se insere na última área onde a vegetação da encosta do Corcovado, ainda preservada pelo Parque Lage, atinge a Lagoa, (...) como porque representa o fruto de um apaixonado e generoso esforço pessoal que, conquanto equivocado, merece a devida proteção" (Costa apud Pessôa, 1998: 284, grifos nossos).

Devolvendo, ainda, a responsabilidade ao imbroglio político que enfrentava o Estado da Guanabara com o destino da casa, Costa provocou duas reações: tornou-se, sem dúvida, omisso em relação à preservação da paisagem que ele mesmo destacara, e acabou chancelando as atitudes contraditórias entre a administração pública e a ascendência privada sobre o Estado da Guanabara. Culpas impossíveis de serem retiradas de suas costas.

A segunda definição requerida do IPHAN ocorreu em 14 de dezembro de 1973, por meio de um abaixo-assinado promovido pelo $I A B$, com apoio do Clube de Engenharia do Rio de Janeiro, e reuniu 500 assinaturas de diversas personalidades dos cenários cultural e político, além de interessados na causa. A petição evocava o valor ambiental da área, amenizando a argumentação em prol do valor arquitetônico, exatamente como sugerira Lucio Costa poucos dias antes em seu parecer. Os signatários apelavam ainda ao Decreto-Lei $n^{\circ} 25$, o qual previa que

'estão sujeitos a tombamento os monumentos naturais, bem como os sítios e paisagens que importe conservar e proteger pela feição notável com que tenham sido dotados pela natureza ou agenciados pela indústria humana' e, considerando que o SOLAR MONJOPE (...) se enquadra perfeita e exatamente nos termos e no espírito do referido Decreto Lei, solicitam seja promovido o tombamento do citado edifício e de toda a área florestada que o circunda (Abaixo-Assinado, apud Processo Iphan 895-T-74, grifos nossos).

Esta cartada arquitetada pelo IAB-GB com o apoio do Clube de Engenharia e de expoentes da intelligentsia nacional como Burle Marx, Carmen Portinho e Juarez Távora, entre tantos outros, parecia definitiva no sentido de angariar o beneplácito do IPHAN, mas não foi assim. 0 despacho derivado de tal petição dizia que o IPHAN já tinha tomado sua decisão quando, a pedido do Diretor, Renato Soeiro, Lucio Costa exarara o primeiro parecer, remetendo mais uma vez ao Estado da Guanabara a definição sobre a manutenção do conjunto mata urbana - edifício (Despacho de 4 dez. 1973, apud Processo Iphan 895-T-74).

O IPHAN seria colocado em evidência em mais um incidente. Em 21 de fevereiro de 1974, José Marianno Neto encaminhou ao instituto uma carta doando uma "pia batismal" do conjunto franciscano de Paraguaçu, que teria sido o grande celeiro de peças coloniais para José Marianno Filho. O IPHAN foi célere em proceder ao tombamento da peça, a qual foi inscrita no Livro das Belas Artes sob número 515, folha 94, em 25 de abril. Tal tombamento, o único de fato a incidir sobre todo o complexo do Solar Monjope, parecia abrir uma senda para a salvaguarda. 
Entretanto, uma carta encaminhada por José Marianno Neto em 24 de maio expunha problemas na relação Instituto - proprietários. Tendo o IPHAN enfrentado toda a burocracia atinente à lei de licitação, que forçava a contratação de uma empresa para a retirada da peça e seu traslado, o herdeiro e doador em questão informava que, diante da demora do IPHAN em retirar a peça doada, e com base no artigo 1.181 do Código Civil, parágrafo único, resolvera

revogar a doação, pois o donatário (o Patrimônio Histórico), se atrazou [sic], comprovadamente, no cumprimento da obrigação que era a de apanhar a PIA [sic] no prazo concertado. A peça acha-se agora sob minha guarda e zelo. $E$, desde que tombamento não é desapropriação, entendo que posso continuar a guardá-la, mesmo tombada, porque tenho um tradicional interesse na conservação das belas obras de arte (José Marianno Carneiro da Cunha Neto, apud Processo 895-T-74, grifos nossos).

A peça, de fato, permanece tombada, mas seu paradeiro é incerto. 0 próprio IPHAN, ao descrever 0 artefato em seu sítio da internet, permite inferir que não a conhece, pois a descreve a partir de fotografia pertencente ao acervo pessoal do arquiteto Francisco Saldanha. ${ }^{15}$ Curioso, também, é perceber que naquele momento o proprietário do Solar usava os argumentos da sociedade que se mobilizou para salvar a casa: tombamento não é desapropriação.

O Solar Monjope, por fim, foi desagregado, tanto arquitetônica quanto decorativamente. ${ }^{16}$ Mas o que, afinal, restou do Solar Monjope em termos simbólicos e materiais? Além das referências em livros de arte e arquitetura, de um pequeno painel de azulejos no Museu Histórico Nacional, da pia batismal desaparecida, há dois dados que esta espécie de batalha preservacionista rendeu. Um, material, foi a manutenção do muro de fecho da propriedade, que, embora descaracterizado, ainda permite ver algumas soluções espaciais da antiga casa. A outra foi-nos revelada pelo trabalho de Maria Harlindis T. H. Vianna, que estudou a regulamentação de áreas de entorno no IPHAN, no Rio de Janeiro. Argumenta a pesquisadora, em sua monografia de especialização, a razão de o conjunto de seis torres de apartamentos ter ficado com gabarito mais baixo, e ter mantido grande parte da vegetação pré-existente. Diz ela que

À época, a legislação da Prefeitura Municipal permitia para o local prédios de 18 pavimentos. 0 IPHAN, com o apoio dos moradores e com o objetivo de conter a forte especulação imobiliária na região, com construções de gabaritos altos, em 1978 elaborou a Portaria n. 12/78, que reduzia a altura dos prédios para apenas seis pavimentos, visando garantir a visibilidade e a ambiência do Corcovado, e outros bens tombados no bairro (Vianna, 2010: 31).

De fato, o condomínio construído, chamado de Parque Monjope, seguiu um gabarito mais baixo, e praticamente tem suas seis torres desaparecendo por entre o arvoredo que, efetivamente, foi em grande parte preservado. 
0 estudo do Solar Monjope revela o quanto as instituições do patrimônio tiveram como prática preservacionista apenas a aplicabilidade do tombamento, relegando a planos secundários, ou mesmo desconsiderando, atividades de inventariação, registros gráficos e visuais, hoje considerados também medidas de acautelamento pela Constituição Federal de 1988.

A investigação do circuito social desta obra mostra-se como um caminho metodologicamente aparelhado para a compreensão de seu impacto no cotidiano das pessoas, a ponto de se deflagrarem lutas preservacionistas. Assim, afirmamos que as manifestações que envolveram a preservação do Solar Monjope em 1974 não foram episódicas, e muito menos estavam inscritas numa luta emanada dos gabinetes da "repartição" do patrimônio contra ecléticos e modernos, apenas. Elas eram sociais, também. Havia agendas ocultas, envolvendo grupos econômicos, de comunicação e políticos, que embora tenham vencido a batalha com 0 desparecimento da edificação, promoveram, como mostrado, a emergência de leis de preservação ambiental na cidade e a movimentação da sociedade civil.

Dessa maneira, a discussão atinente à preservação brasileira precisa incorporar também as razões que levaram edifícios ao desaparecimento. Esta é a grande contribuição que a história da "não-preservação" tem a dar na definição de políticas públicas e para a história social urbana.

\section{NotAS}

1 Outros participantes do certame foram Lucio Costa e Nereu Sampaio, Roberto Magno de Carvalho - que recebeu Menção Honrosa - e Gabriel Fernandes (O Malho, 1924; Pinheiro, 2011: 150; Kessel, 2009).

2 Como o próprio José Marianno divulgava, a autoria da "Casa-Manifesto" era exclusivamente dele. Uma explicação dada por Angyone Costa para isso é que "tudo, no solar de Monjope, é obra sua, tendo sido o risco da casa traçado por arquitetos que trabalharam sob sua rigorosa direção" (Costa, 1927: 292).

3 A comissão era formada pelos arquitetos John Gallen Howard, professor na Stanford University, Kenneth Mullichson, do American Institute of Architects - AIA, Warren Powers Laird, deão da Fine Arts School da Universidade da Pensilvânia, Frank R. Watson, vice-presidente do comitê de assuntos internacionais do AIA, e Edwin Morgan, embaixador americano no Rio, além de ex-alunos da Universidade da Pensilvânia radicados na capital federal de então, como Edgard Pinheiro Vianna, William Procter Curtis e John Pollock Curtis.

4 Zózimo Barroso do Amaral (1941-1997) estreou no jornalismo ainda jovem no jornal O Globo, sob pseudônimo de Carlos Swann. Em 1969 mudou-se para o Jornal do Brasil, passando a assinar sua coluna com seu nome. 0 Jornal do Brasil, tentando apagar a marca registrada do que Zózimo praticava no Globo, apresentou-o como "um jovem de 27 anos com cinco de jornalismo. Faz questão de esclarecer que não é colunista social e que sob sua assinatura o leitor encontrará noticiário diversificado, voltado para a vida da cidade" (Jornal do Brasil, 4 fev. 1969, também citado em http://www.observatoriodaimprensa.com.br/artigos/asp21112001993. htm, acesso 21 mar. 2016). 0 interesse pelas "coisas da cidade", que expressou no jornalismo, explica, em parte, a razão de Zózimo ter-se envolvido na polêmica do Solar Monjope. 
50 valor de 27 milhões de cruzeiros, à época, foi estimado como algo em torno de 5 milhões de dólares, quantia vultosa.

6 A matriarca Violeta Siciliano falecera em 1972, e o casal José Marianno Neto e Silvia Gueiros Marianno havia se mudado para a Gávea. Os outros dois filhos, Marcus e Claudio, já haviam se mudado anos antes.

70 caso mais notório foi o do Palácio Monroe, antiga sede do Senado Federal, na Cinelândia.

8 Mario de Andrade previa, na Seção da Arte Popular, alínea "a", acerca de Monumentos, que "devem ser conservados exemplares típicos das diversas escolas e estilos arquitetônicos que se refletiram no Brasil. A data para que um exemplar típico possa ser considerado histórico e documental deve ser fixada de 1900 para trás, por exemplo, ou de cinquenta anos para trás" (Andrade, 1936, in Cavalcanti, 1993: 42, grifos nossos).

9 Esse Decreto Lei organizava as atividades de preservação pelo Estado da Guanabara.

10 Marcos Tito Tamoyo da Silva (1926-1981) foi prefeito do Rio de Janeiro, quando a antiga capital passou a estar inserida no Estado da Guanabara, período conhecido como Pós-Fusão. Era engenheiro, formado pela Faculdade Nacional de Engenharia, depois incorporada à UFRJ.

11 Concedida em 3/10/2007 no Arquivo da Cidade, Rio de Janeiro, e transcrita no livro Memórias do Rio: 0 Arquivo Geral da Cidade do Rio de Janeiro em sua trajetória republicana, de 2011.

12 Dirceu Araújo Nogueira, general do Exército, foi ministro dos Transportes de Ernesto Geisel de 15 de março de 1974 a 15 de março de 1979 (Kushnir e Horta, 2011: 450).

130 IAB-GB foi aos jornais pedir esclarecimento a Chagas Freitas sobre tal "injuridicidade", uma vez que 0 mesmo Decreto-Lei havia tombado, por exemplo, o Theatro Municipal pouco tempo antes (Jornal do Brasil, 24 nov, 1973).

14 Ibrahim Sued (1924-1995) é conhecido como o "jornalista de eventos sociais" por conta de sua coluna publicada de 1954 até 1995 no jornal O Globo. Ali desenvolveu coberturas políticas e culturais de uma forma mais palatável ao público, e alcançou notoriedade e respeito da classe alta carioca. Por conta da entrada e do livre trânsito nesse universo, foi muitas vezes mobilizado para emitir opiniões e ajudar em negociações econômicas e políticas. Este papel é verificável no caso do Solar Monjope.

15 Conferir: http://portal.iphan.gov.br/ans.net/tema_consulta.asp?Linha=tc_belas.gif\&Cod=1038. Acesso 21 jul. 2015.

16 Existe um trecho de painel de azulejos no Museu Histórico Nacional, proveniente do Solar Monjope, possivelmente doado por um dos herdeiros.

\section{REFERÊNCIAS BIBLIOGRÁFICAS}

ANDRADE, Mario de. Anteprojeto do Patrimônio. In: CAVALCANTI, Lauro (org.). Modernistas na repartição. Rio de Janeiro: Editora da UFRJ; Paço Imperial; Tempo Brasileiro, 1993, p.39-56.

ATIQUE, Fernando. Arquitetando a "boa vizinhança": a sociedade urbana do Brasil e a recepção do mundo norte-americano, 1876-1945. (Tese de Doutorado). São Paulo: FAU-USP, 2007.

Arquitetando a "boa vizinhança": arquitetura, cidade e cultura nas relações Brasil-Estados Unidos, 1876-1945. Campinas: Pontes/FAPESP, 2010. 
Urdiduras continentais no debate acerca do Mission Style. Notas sobre o pan-americanismo na arquitetura neocolonial, Revista Eletrônica da ANPHLAC. São Paulo, ANPHLAC, n. 10, 2011, p. 174-212.

AZEVEDO, Ricardo Marques de. Las ideas de Ricardo Severo y la relación con el academicismo. In: AMARAL, Aracy. Arquitectura neocolonial: América Latina, Caribe, Estados Unidos. São Paulo: Fondo de Cultura Económica/Memorial da América Latina, 1994.

BANDEIRA, Julio; MACHADO, José de Paula. Solar de Monjope. Rio de Janeiro: Reler, 2008.

BRASIL. Decreto-Lei n.25, de 30 de novembro de 1937. In: IPHAN. Coletânea de Leis sobre Preservação do Patrimônio. Rio de Janeiro, IPHAN, 2006.

BRUAND, Yves. Arquitetura contemporânea no Brasil. São Paulo: Perspectiva, 1991.

CAMPOS NETO, Candido. Os rumos da cidade: urbanismo e modernização em São Paulo. São Paulo: Editora Senac, 2002.

CASTRO, Sônia Rabello de. O Estado na preservação de bens culturais - o tombamento. Rio de Janeiro: IPHAN, 2009. Série Reedições do Patrimônio.

CAVALCANTI, Lauro (org.). Modernistas na repartição. Rio de Janeiro: Editora da UFRJ; Paço Imperial; Tempo Brasileiro: 1993.

COSTA, Angyone. A inquietação das abelhas: inquérito sobre a vida artística brasileira. 0 que pensam e 0 que dizem os nossos pintores, esculptores, architectos e gravadores sobre as artes plásticas no Brasil. Rio de Janeiro: Pimenta de Mello e Cia., 1927.

COSTA, Lucio. Registro de uma vivência. São Paulo: Empresa das Artes, 1995.

CUNHA FILHO, José Marianno Carneiro da. Estudos de arte brasileira. Rio de Janeiro: Est. de Artes Gráficas, 1942.

. As características do estilo arquitetônico nacional, O Jornal, Rio de Janeiro, 8 jul. 1931.

. Right or wrong, it is my house. O Jornal, Rio de Janeiro, jul. 1931, s.p.

. Definindo mais uma vez meu pensamento. In: Architectura: mensário de arte. Rio de Janeiro, a.l, n.7, dez. 1929, p. 9 -10.

DECOURT, André. Favela da Praia do Pinto, vista da Pedra do Baiano - circa 1938. Matéria Postada no Blog Foi um Rio que Passou em Minha Vida em 9 de maio de 2012. Disponível em: www.rioquepassou.com. br/2012/05/09/favela-da-praia-do-pinto-visto-da-pedra-do-baiano-circa-1938/. Acesso em 20/11/2012.

DRAYER, Ruth A. Nicholas and Helena Roerich: the spiritual journey of two great artists and peacemakers. Wheaton: Quest Books, 2003.

HARGREAVES, Manuela. Colecionismo e colecionadores, um olhar sobre a história da arte na $2^{\mathrm{a}}$ metade do século XX. Porto: Fundação Cupertino de Miranda, 2014. Disponível em: http://ler.letras.up.pt/uploads/ficheiros/13020.pdf. Acesso 20 mar. 2016.

IPHAN. Coletânea de Leis sobre Preservação do Patrimônio. Rio de Janeiro, IPHAN, 2006.

IV CONGRESO Panamericano de Arquitectos. Revista de Arquitectura. Buenos Aires: Sociedad Central de Arquitectos, n. 112, abr. 1930, p. 259-399. 
JAUSS, Hans Robert. Toward an aesthetic of reception. Twin Cities: University of Minnseota Press, 1982.

KESSEL, Carlos. Arquitetura neocolonial no Brasil: entre o pastiche e a modernidade. Rio de Janeiro: Jauá Editora, 2008.

KIPLING, Rudyard. Brazilian sketches / As crônicas do Brasil(Edição Bilíngue). Rio de Janeiro: Landmark, 2006.

KUSHNIR, Beatriz; HORTA, Sandra (orgs.). Memórias do Rio: o Arquivo Geral da Cidade do Rio de Janeiro em sua trajetória republicana. Rio de Janeiro: Imago, 2011.

LEMOS, Carlos A. C. Alvenaria burguesa: breve história da arquitetura residencial de tijolos em São Paulo a partir do ciclo econômico liderado pelo café. $2^{\text {a }}$ ed. São Paulo: Nobel, 1989.

MARQUES, Pedro. Olegário Mariano. São Paulo: Imprensa Oficial / Rio de Janeiro: Academia Brasileira de Letras, 2012.

MATEUS, Eliane Elias. A proteção do patrimônio cultural e o tombamento. In: Leopoldianum: revista de estudos e comunicações da Universidade Católica de Santos. Santos, n. 93-93, jan-ago 2008, p.117-134.

MEC / SPHAN. Proteção e revitalização do patrimônio cultural no Brasil: uma trajetória. Brasília: Fundação Pró-Memória, 1980.

MELLO, Joana de. Ricardo Severo: da arqueologia portuguesa á arquitetura brasileira. São Paulo: FAPESP, 2007.

MINGORANCE, Ricardo. O debate sobre a arte, a arquitetura e a cidade do século XIX em José Marianno Filho. (Trabalho de Conclusão de Curso). Guarulhos: Universidade Federal de São Paulo / Fundação de Amparo à Pesquisa do Estado de São Paulo, 2012.

A Apreciação de José Marianno Filho sobre a arte, a arquitetura e a cidade do século XIX. (Relatório Final da Bolsa de Iniciação Científica FAPESP). Guarulhos: EFLCH/UNIFESP, 2011.

PESSOA, José (org.). Lucio Costa: documentos de trabalho. Rio de Janeiro: Edições do Patrimônio, 1998.

PINHEIRO, Maria Lucia Bressan. Neocolonial, modernismo e preservação do patrimônio no debate cultural dos anos 1920 no Brasil. São Paulo: EDUSP; FAPESP, 2011.

PREFEITURA DA CIDADE DO RIO DE JANEIRO. Memória da destruição. Rio, uma história que se perdeu (18891965). Rio de Janeiro: Secretaria da Cultura; Arquivo da Cidade, 2002.

Revista de Arquitectura. Número especial referente al IV Congreso Panamericano de Arquitectos y Exposicion de Arquitectura realizado em Río de Janeiro. Buenos Aires: Sociedad Central de Arquitectos, n. 116, a. XVI, ago. 1930, p. 468-556.

REZENDE, Vera. L. F. M. As transferências internacionais e o urbanismo modernista na cidade do Rio de Janeiro. Anais do VI Seminário de História da Cidade e do Urbanismo (CD-ROM). Natal: Mediashow Multimédia por solicitação do Programa de Pós-Graduação em Arquitetura e Urbanismo da UFRN, 2000. v. 1.

RODRIGUES, Marly. Imagens do passado: a instituição do patrimônio em São Paulo, 1968-1987. São Paulo: Editora da UNESP; Condephaat; FAPESP, Imprensa Oficial, 2000.

SEVERO, Ricardo. A arte tradicional do Brasil: a casa e o templo. In: O Estado de São Paulo, São Paulo, 26 jul. 1914. VIANNA, Maria Harlindis Teresa Hardman. Portaria de entorno do IPHAN - Política de gestão para implantação de um sistema de fiscalização do patrimônio cultural. (Monografia de Especialização). Rio de Janeiro: Universidade Candido Mendes, 2010. 


\section{Filmes}

A primeira missa, 1961. Direção de Lima Barreto. Cor. 35mm. 90min.

Sangue Mineiro, 1929-1930. Direção de Humberto Mauro. PB. 35mm. 85min. Mudo.

\section{PERIÓDICOS CITADOS}

A Noite, 15 out. 1923.

Correio da Manhã, 8 abr. 1928, s/p; 11 jul. 1928, p. 8; 18 jun. 1929, p.7; 22 jun. 1928, p. 10; 21 jun. 1930, p.6. Diário de Notícias, 23 nov. 1973.

Ilustração Brasileira, 1923; 1927, s/p.; jul. 1930.

Jornal do Brasil, 22 out. 1973, s/p.; 14 nov. 1973, s/p.; 15 nov. 1973, p. 18; 17 e 24 nov. 1973; 5 set. 1975.

Manchete, 15 abr. 1967, p. 68-71.

O Cruzeiro, 30 jun. e 5 jul. 1930, p.17-19.

O Dia, 21 nov. 1975.

O Estado de S. Paulo, 29 nov. 1973.

O Globo, 7 e 11 dez. 1973; 4, 6, 10 e 19 jul. 1974; 11 out. 1975.

O Jornal, 28 jun. 1927, p.3; 8 jul. 1927, p.11; 10 ago. 1928; 20 jun. 1930, p.12; 21 jun. 1930, p. 12; 22 jun. 1930, p. 9; 24 jun. 1930, p.1; 25 jun. 1930, p.12; 12 fev. 1939, p.13.

O Malho, 1924.

O Paiz, 21 jun. 1930, p.5.

Revista da Semana, 28 jul. 1928, p.22.

Revista de Architectura, n. 116, ago. 1930.

Sétimo Céu, abr. 1970.

Última Hora, 22 nov. 1973.

Veja, 28 nov. 1973. Disponível em: veja.abril.com.br/acervodigital/home.aspx. Acesso em 20 jan 2015. 